\title{
The protective effect of a fire-retardant coating on the insulation failure of PVC cable
}

\author{
Ji Wang ${ }^{\mathrm{a}}$, Zhong-Jun Shu ${ }^{\mathrm{a}, *}$, Zhen Chen ${ }^{\mathrm{b}}$ \\ a Fire Protection Engineering Department, Chinese People's Armed Police Forces Academy, Langfang 065000, China \\ ${ }^{\mathrm{b}}$ Institute of Mechanics, Chinese Academy of Science, Beijing 100190, China
}

\section{A R T I C L E I N F O}

\section{Article history:}

Received 16 April 2013

Received in revised form 10 July 2013

Accepted 10 July 2013

Available online 25 July 2013

\section{Keywords:}

PVC insulated cable

Fire retardant coating

Failure time

ISO 834 fire scenario

\begin{abstract}
A B S T R A C T
The failure time of polyvinyl chloride (PVC) insulated power cables was studied using an infrared radiation heating furnace and insulation resistance measurements. The temperature-time curve inside the furnace was similar to that of the ISO 834 standard. Two popular fire protection methods were employed for the cables; one method applied fireretardant coatings directly on the cable surface, and the other inserted the cables into metal conduits coated with structural steel fire-retardant coating. The results showed that for both protection methods, the failure time of the cable increased with the thickness of the coating. However, if the cable coatings were thicker than $1.5 \mathrm{~mm}$, the coating will crack in the case of cable movement. When the steel structural coating was thinner than $1 \mathrm{~mm}$ or thicker than $3 \mathrm{~mm}$, the protective effect was not remarkable for the relatively small expansion multiple. For the longest failure time of the cables, less than $10 \mathrm{~min}$ in these tests, neither of the two methods was effective in protecting the electrical cables that supply power (on transmit a signal) to equipment required to operate over a relatively long duration in fire conditions.
\end{abstract}

(c) 2013 Elsevier Ltd. All rights reserved.

\section{Introduction}

With improved fire safety requirements for buildings and public facilities, increasing attention has been directed to the fire protection performance of cables. An important design goal for cables is to maintain the circuit integrity and guarantee that the working time of the cable is longer than the duration of the fire [1,2]. Generally, to guarantee a sufficient working time for safety equipment, either the cables or systems must be designed to be resistant to fire. In standard conditions, these cables or systems can provide electrical continuity for (15), 30, 60, 90 or even 120 min.

Polyvinyl chloride (PVC) is one of the most widely used polymers in the field of electrical and control cables. When considering flammability in general, PVC is essentially considered to be self-extinguishing. However, as a result of additives used during processing, PVC is able to support flame spread along its length. Passive fire protection includes coatings and firestops, as well as the use of inherently flame-retardant materials [3]. The spread of fire along PVC sheathed electrical cables may be diminished by using either flame-retardant smoke-suppressant (FRSS) additives, AND/OR by applying fire-retardant intumescent coatings to the surface of the cable sheath. When the FRSS additives are concerned, plasticized PVC compositions incorporating a molybdenum-based organic (MBO) complex have been found to offer excellent smoke suppression, and have a fairly high limiting oxygen index (LOI) - particularly when plasticized with a phosphate plasticizer (i.e. they act as an FRSS additive). While in applying the fire-retardant intumescent coatings, two approaches can be used to improve their fire

\footnotetext{
* Corresponding author. Address: Chinese People’s Armed Police Forces Academy, Xichang Road 220\#, Anci District, Langfang City, Hebei Province 065000, China. Tel.: +86 13785639000.

E-mail addresses: wanghutty@163.com (J. Wang), shuzhongjun119@126.com (Z.-J. Shu).
} 
resistance properties: one is the insertion of the cables into a fire-retardant coated conduit, and the other is the application of a fire-retardant coating on the cable surface. However, it is not clear whether these two methods are sufficiently effective to enhance the fire resistance of common cables, and few regulations and reference data exist for either of these protection methods.

Currently, fire-retardant coating for cables is primarily used to improve such fire performance properties as flammability, flame spread, and smoke production. Consequently, most of the national criteria associated with fire-retardant steel coatings focus on the performance with respect to the resistance of the surface of the cable to fire propagation and neglect improvement in the regular operating time of the cable under fire conditions [4,5]. Many standards exist for testing the resistance of electrical cables to fire or the associated protective systems and components. However, those standards are not applicable for cables protected by fire-retardant coatings [6-10]. Moreover, in addition to improved fire exposure lifetime, further criteria for FRSS intumescent coatings should be a significantly low level of smoke generation, along with zero flame spread when exposed to standard test conditions. Many tests of the cable's capacity for trouble-free operation under heat and fire conditions have been conducted. An example set of tests was conducted by Murphy [11]. In this program, forty-three tests were conducted using ethylene rubber (EPR) and cross-linked polyethylene cables (XLPE), and the relationships between heat flux, temperature and cable failure time were acquired. Shu et al. [12] studied the failure time and corresponding temperature of XLPE and fire resistant PVC insulated cables. The cables were arranged in a cable tray and inserted into a metal conduit and a PVC conduit. Saxena et al. [13] studied the fire protection performance of a fire-retardant intumescent coating for PVC insulated power cables. The fire retardant coating employed was determined to be quite effective in reducing the flammability of electrical cables. The circuit failure time was also increased significantly for the coated cables, and it was concluded that the circuit failure time depended on the cable diameter and coating thickness. In most of the above tests, the cables were not protected with a fire-retardant coating or the heat source for the tests consisted of a liquefied petroleum gas (LPG)-fueled flame, conditions which deviate from certain real fire scenarios. In real projects, most cables are laid in the ceiling or floor compartments, which are mainly heated by thermal radiation. Therefore, the applicability of these conclusions is limited.

In this paper, the fire protection methods of a fire-retardant-coated conduit and direct cable coating were both tested. The insulation failure time of PVC insulated power cables protected by varied thicknesses of a fire-retardant coating were studied under ISO 834 standard fire conditions. The experimental apparatus consisted of an infrared radiation heating furnace and an insulation resistance measurement device, both specially produced. With the goal of providing adequate power over time to the electrical apparatus, particularly the fire-fighting equipment, the results of this study may be used as a reference for selecting an appropriate strategy for cable fire protection or cable installation methods.

\section{Experiments}

\subsection{Experimental material and apparatus}

The insulation and jacketing material of the cable specimen chosen for this test program was PVC, a common material in many cable projects [14]. The cable consisted of four copper conductors, and the cross-sectional area of each conductor was $2.5 \mathrm{~mm}^{2}$. Fig. 1 shows the cross-sectional diagram of the cable specimen. Two types of intumescent fire retardant coatings were used in this study, a fire-retardant cable coating and a metal structural fire-retardant coating. The conduit consisted of galvanized steel, and the diameter and thickness of the conduit wall were $32 \mathrm{~mm}$ and $1.2 \mathrm{~mm}$, respectively. All of the experimental material was chosen from off-the-shelf products.

An infrared radiation heating furnace was employed to provide the different fire scenarios. The furnace was $0.8 \mathrm{~m}$ long by $0.75 \mathrm{~m}$ wide by $0.8 \mathrm{~m}$ high, and the rated voltage was $380 \mathrm{~V}$. Inside the furnace, 24 radiant heating lamps were installed length-wise and evenly spaced in the cylindrical shroud, and the diameter of the interior surface of the shroud was $0.33 \mathrm{~m}$. The rated power of each radiant heating lamp was $2.0 \mathrm{~kW}$, and thus the total output power of the furnace was

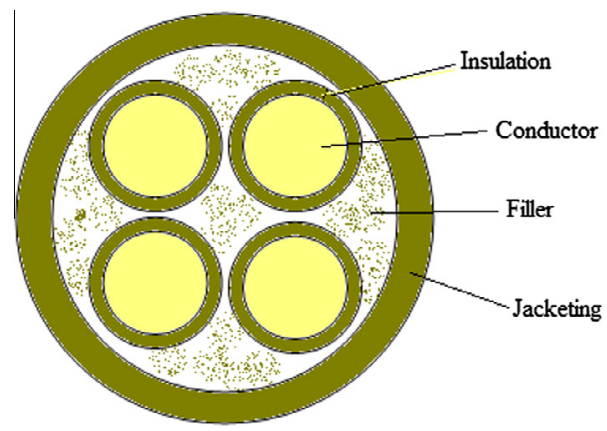

Fig. 1. Cross-sectional diagram of cable specimen. 
$48 \mathrm{~kW}$. Different output power levels were available by adjusting the furnace controller, and the furnace inner temperature was varied correspondingly. The control ranged from $0 \%$ to $100 \%$, which was able to meet different fire scenarios. During the tests, the cable specimen was located in the center of the furnace (both vertically and horizontally) and was therefore exposed to the full $360^{\circ}$ of radiant heat. To decrease the exit of hot air and simulate a closed heating condition, two asbestos-filled insulation lids were placed at the ends of the furnace.

The data acquisition system consisted of a paperless recorder and an insulation resistance measurement device. The paperless recorder was used to read and record the temperature of a thermocouple instrumented in the cable specimen. The insulation resistance measurement device was used to monitor and record the changes in the conductor-to-conductor insulation resistance. The measurement range of the device was from $1 \times 10^{3} \Omega$ to $1 \times 10^{10} \Omega$. During the experiments, when the conductor-to-conductor resistance dropped to $50 \mathrm{k} \Omega$, representing a cable condition close to breakdown, the device alarm would beep intermittently to remind the experimenter to end the test. When the conductor-to-conductor resistance dropped to $8.5 \mathrm{k} \Omega$, representing full cable breakdown, the device alarm would beep continuously to remind the experimenter to end the test immediately.

Fig. 2 shows the structure of the infrared radiation heating furnace and the data acquisition system used in this experimental study.

\subsection{Preparation of specimen}

The cable specimens were $1.0 \mathrm{~m}$ in length, and the jacketing material was removed over a length of $0.05 \mathrm{~m}$ from both ends. In the center of the cable, a $1.0-\mathrm{cm}$ slice was cut through the jacketing to the inside, and a type $\mathrm{K}$ thermocouple was placed under the cable filler. To avoid the effects of slicing, the distance between the slice edge and the end of the thermocouple was approximately $2 \mathrm{~cm}$. The diameter of the thermocouple was $1 \mathrm{~mm}$. The inserted thermocouple was secured with fiberglass tape, and the tape was wrapped around the cable to close the slit and hold the thermocouple in place.

Before application of the fire-retardant coating, the surface of the cable was cleaned, and the cable surface and the fiberglass tape was evenly coated. The specimens were coated with different amounts of coating to create a $0-1.5 \mathrm{~mm}$ dry-coating thickness. Specimens with six different coating thicknesses were tested.

Before applying the metal structure fire retardant coating on the conduit, the surface of the conduit was cleaned. The dry coating thickness on the conduits ranged from $0 \mathrm{~mm}$ to $3.5 \mathrm{~mm}$, and specimens with eight different coating thicknesses were tested.

\subsection{Fire exposure scenario}

Generally, only surfaced cables installed in buildings can be protected using a fire-retardant coating (i.e., those cables that would be directly exposed to fire). The fire scenario simulated in this program was based on the ISO 834 standard fire condition, which is widely employed in the evaluation of fire-retardant performance of building components and is consistent with most of the real fire scenarios that occur in buildings. Therefore, the test fire scenario was representative, and the experiment result was assumed as applicable and reliable. The fire scenario was created by regulation of the output power of the furnace via the furnace controller. Because the furnace was sealed, the inner temperature of the furnace showed a uniform distribution except for a small drop near the two ends of the furnace. Fig. 3 shows a comparison of the test curve and the ISO 834 standard fire temperature curve.

\subsection{Operating procedure failure criteria}

The operating procedure was separated into three distinct segments: pre-test, test, and post-test. In the pre-test period, the prepared cable specimen was laid in the center of the furnace, two insulation lids were installed at both ends of the

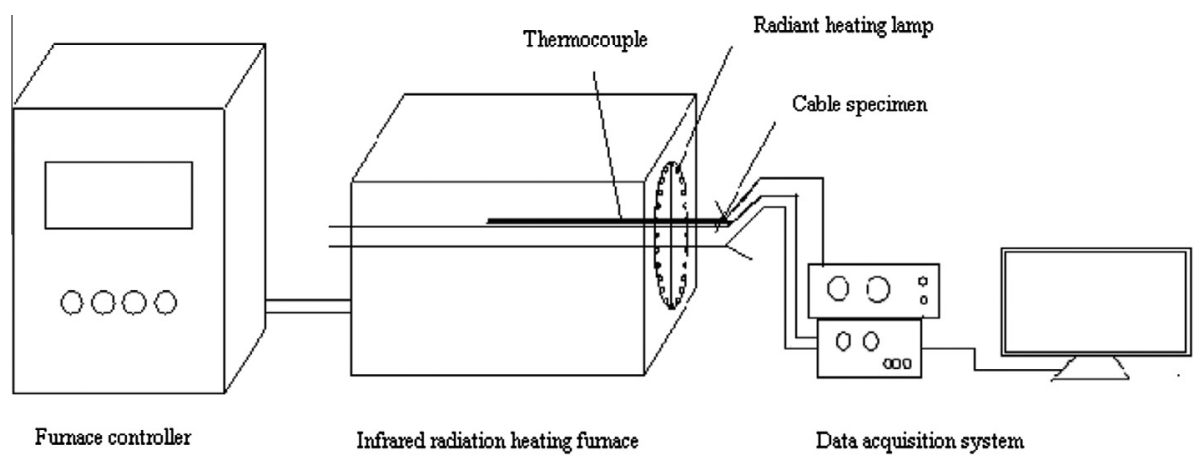

Fig. 2. Structure of the test apparatus. 


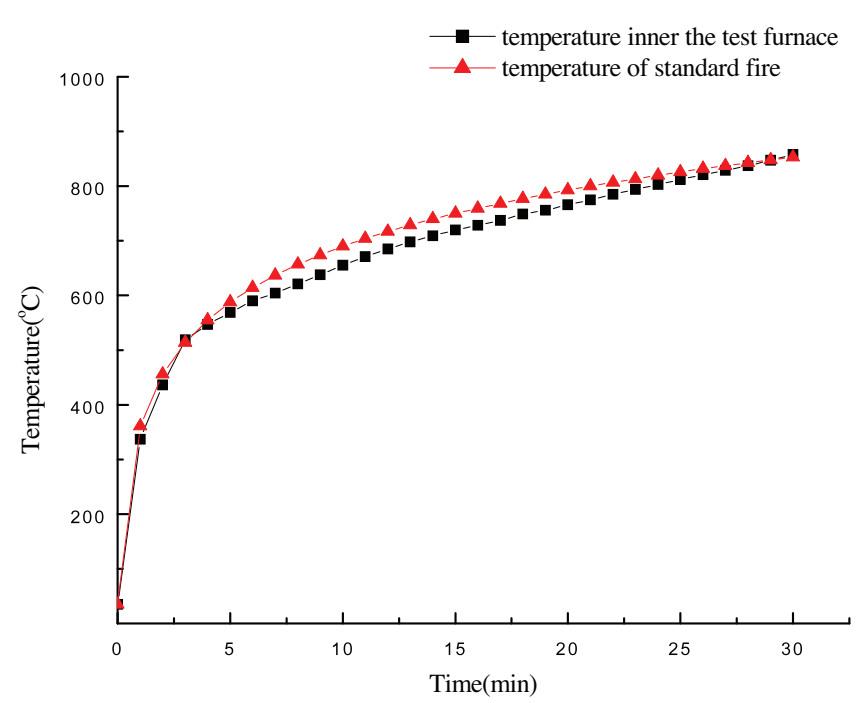

Fig. 3. Temperature versus time curves in the test furnace and the standard fire.

furnace, and two adjacent cable cores were connected with the insulation resistance measurement system at one end, the other ends of the cores were separated to avoid contact with each other, the data transmission wire was connected with the paperless recorder, and the furnace controller was adjusted to a calibration target value. During the test, all data acquisition was monitored to ensure proper operation and to observe the data collected; once the insulation resistance measurement device alarmed continuously, indicating that the resistance had dropped to lower than $8.5 \mathrm{k} \Omega$, the test was immediately concluded. The post-test tasks consisted of data collection and storage in addition to apparatus cleanup.

\subsection{Failure criteria}

In previous electrical cable experimental programs, no consistent failure criterion was used, and each program defined failure in a different way. The various criteria involved cable ignition, flame propagation, the appearance of a short in the circuit, and a drop in insulation resistance by one order of magnitude from its original value, among others. However, it was unclear if any of these criteria were "better" than others. For this cable program, the conductor-to-conductor insulation resistance was used to determine the time-to-failure. Fig. 4 shows the general trend of the conductor-to-conductor insulation resistance of the test cables. As shown, the ordinate indicates the logarithm of the resistance value, and the abscissa indicates the time elapsed.

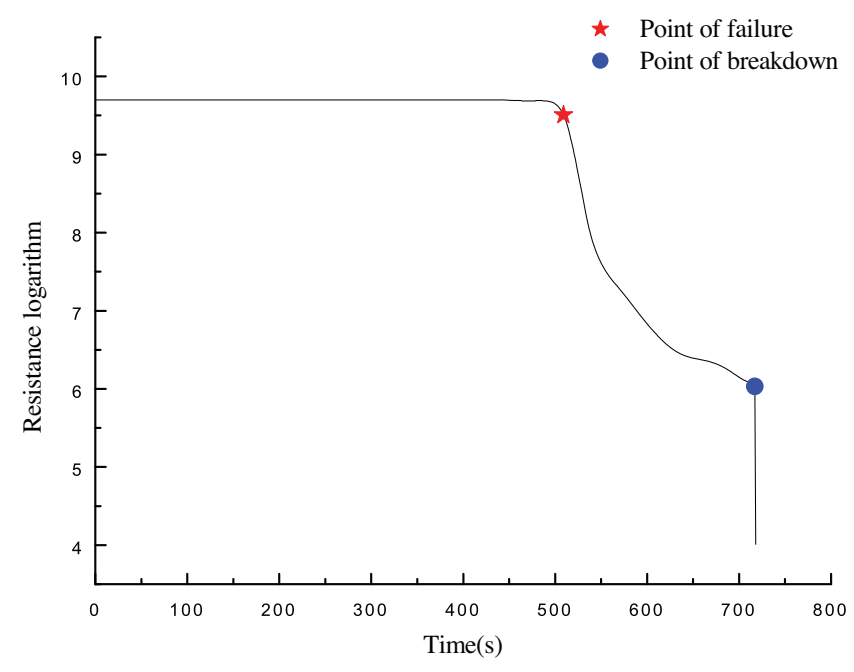

Fig. 4. Logarithm of resistance versus time for test cable. 


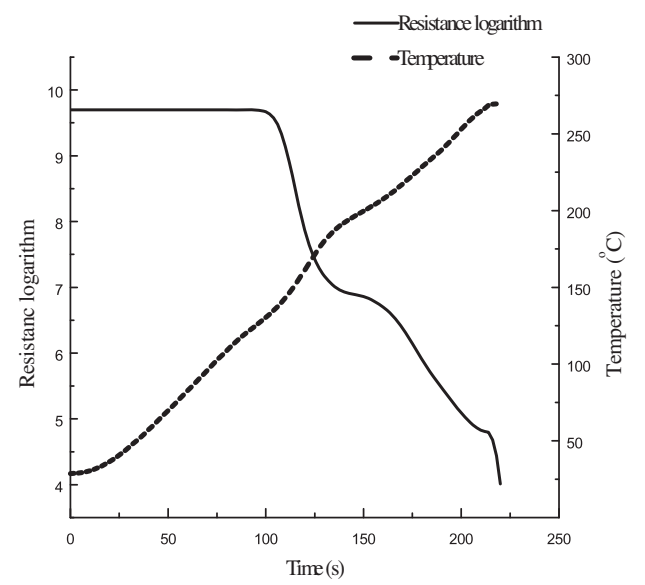

(a) Without fire retardant coating

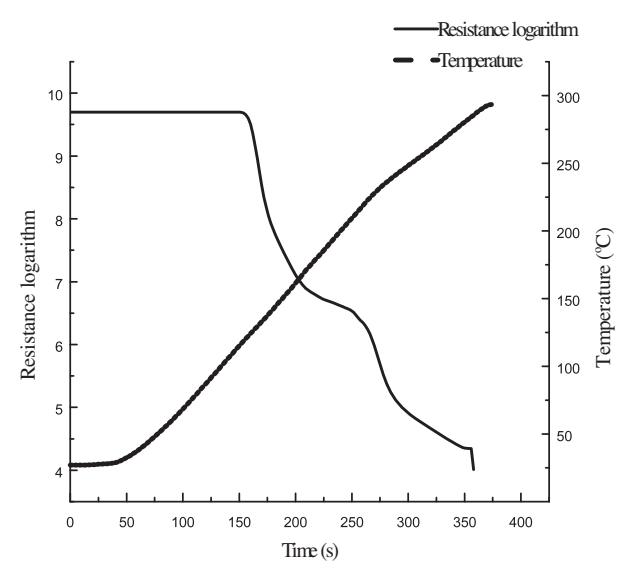

(c) Dry coating thickness of $0.81 \mathrm{~mm}$

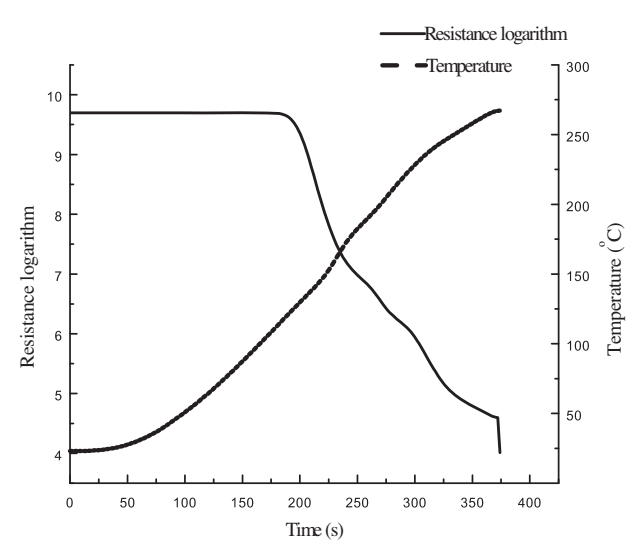

(e) Dry coating thickness of $1.28 \mathrm{~mm}$

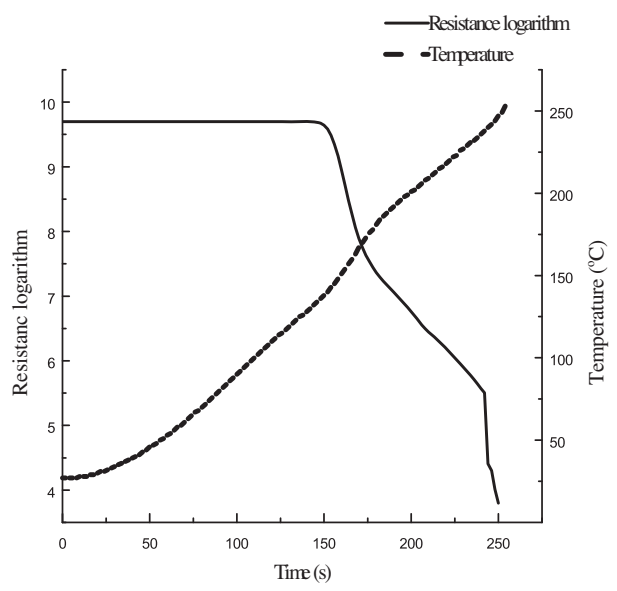

(b) Dry coating thickness of $0.64 \mathrm{~mm}$

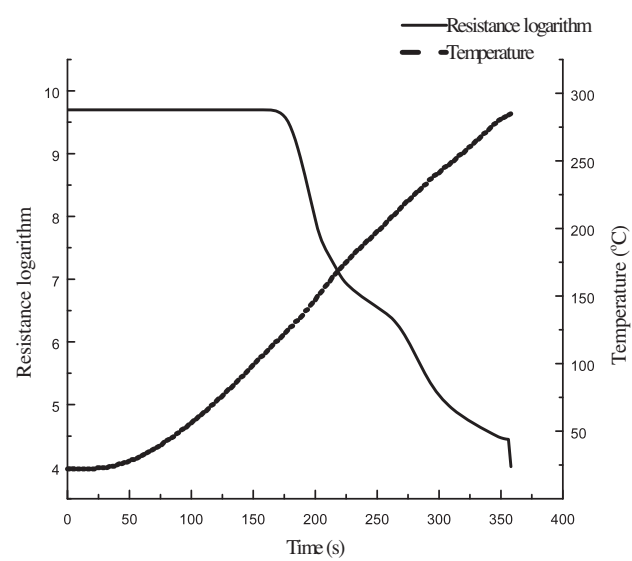

(d) Dry coating thickness of $1.03 \mathrm{~mm}$

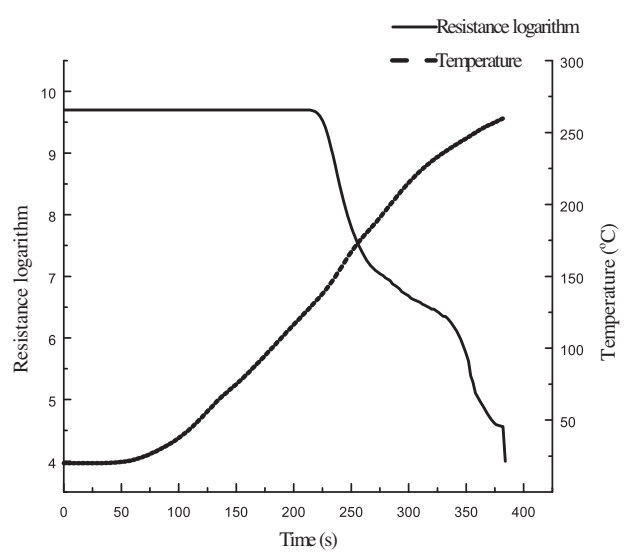

(f) Dry coating thickness of $1.52 \mathrm{~mm}$

Fig. 5. Logarithms of resistance and temperature versus time of PVC cables with different coating thicknesses.

As shown in Fig. 4, at the initial stage, the resistance value does not obviously change, which means that the insulation performance of the conductors remains relatively unaffected. As the inner furnace temperature increases, the resistance value drops rapidly, which indicates the rapid deterioration of the cable insulation performance. Correspondingly, the first inflection in the curve appears and is indicated with a star point in Fig. 4. Next, the insulation resistance value drops con- 
Table 1

Protection effect of different coating thicknesses for insulation failure of PVC cables.

\begin{tabular}{|c|c|c|c|c|c|c|}
\hline $\begin{array}{l}\text { Dry coating } \\
\text { thickness (mm) }\end{array}$ & $\begin{array}{l}\text { Failure } \\
\text { time (s) }\end{array}$ & $\begin{array}{l}\text { Failure } \\
\text { temperature } \\
\left({ }^{\circ} \mathrm{C}\right)\end{array}$ & $\begin{array}{l}\text { Temperature inner } \\
\text { furnace }\left({ }^{\circ} \mathrm{C}\right)\end{array}$ & $\begin{array}{l}\text { Coating thickness after } \\
\text { expansion }(\mathrm{mm})\end{array}$ & $\begin{array}{l}\text { Average expanding } \\
\text { multiple of coating }\end{array}$ & $\begin{array}{l}\text { Prolonging rate of cable } \\
\text { failure time }(\%)\end{array}$ \\
\hline 0 & 106 & 137 & 419.5 & - & - & - \\
\hline 0.64 & 154 & 143 & 471.8 & 14.0 & 21.9 & 45.3 \\
\hline 0.81 & 160 & 124 & 477.2 & 19.4 & 24.0 & 50.9 \\
\hline 1.03 & 180 & 127 & 493.9 & 24.6 & 23.9 & 69.8 \\
\hline 1.28 & 198 & 127 & 507.5 & 27.8 & 21.7 & 86.8 \\
\hline 1.52 & 226 & 139 & 526.4 & 31.3 & 20.6 & 113.2 \\
\hline
\end{tabular}

tinuously until a short circuit occurs and the insulation between the cores reaches breakdown. The second inflection in the curve appears correspondingly and is shown as a dot point in Fig. 4.

Given the above analysis, before the first inflection, the insulation resistance is not significantly damaged and is able to operate normally; when the circuit is shorted, the cable breaks down completely and the cable is absolutely unable to operate. Between the two inflection points, the resistance property of the cable deteriorates rapidly, and the cable exhibits an unreliable working condition: although it can operate temporarily, it is likely to break down at any moment. Therefore, considering the safety and the reliability of the test result for this experimental study, the first inflection point was defined as the failure point, and the corresponding time-to-failure $\left(\tau_{f}\right)$ was used to determine the cable failure temperature.

\section{Results and discussion}

\subsection{Protection effect of different thicknesses of fire-retardant coating on the insulation failure of PVC cables in fire conditions}

The cable specimens with the fire-retardant coating were placed in the radiation heating furnace and monitored for the conductor-to-conductor insulation resistance and the inner temperature of the cable; the procedure and fire scenario were the same as those stated previously. The thickness of the coating ranged from $0 \mathrm{~mm}$ to $1.5 \mathrm{~mm}$, six coating thicknesses were tested and each was tested at least twice. The average value of the repeated tests was presented as the final result. Fig. 5a-f shows the resistance logarithm and temperature of the cable specimen versus time.

Based on the curves in Fig. 5, the related cable failure parameters and protection effect of specimens with different dry coating thickness are listed in Table 1.

Table 1 shows that the average multiple of the tested coating is approximately 20. Compared with the unprotected cable, the fire-retardant coating is effective in improving the fire performance of the cable. The failure time of experimental cable is obviously delayed as a function of the coating thickness, and in this program, the maximum extension of the cable failure time is $113.2 \%$. The equation for the failure time $\left(\tau_{f}\right)$ and dry coating thickness $\left(d_{c}\right)$ can be fitted as:

$$
\tau_{\mathrm{f}}=113.9+1.9 \times 10^{6} \times d_{c}^{1.5}(R 2=0.98)
$$

where the units of $\tau_{f}$ and $d_{c}$ are seconds and meters, respectively.

It is evident from the above equation that the failure time of the cable increases with the thickness of the coating. However, in real cable projects, the thickness of the coating cannot be increased blindly because a thick coating layer will prevent heat emission from the working cable surface, which will speed up the thermal aging of the cable. In addition, when the cable coating is thicker than $1.5 \mathrm{~mm}$, the coating would crack in the case of cable movement. Therefore, according to the actual needs of the cable project, the fire-retardant coating thickness should be limited to approximately $1 \mathrm{~mm}$. With this restriction, the longest failure time in this testing program is $226 \mathrm{~s}$ (less than $4 \mathrm{~min}$ ), and although the prolongation rate is high, it cannot meet the standard requirements for resistance to fire, especially for safety installations that must continue to operate in the case of fire. Thus, the fire retardant alone is not sufficient to protect electrical cables that must supply power to equipment required to operate for a given length of time under fire condition.

\subsection{Protection effect on insulation failure of PVC cables for insertion in metal conduit with different coating thicknesses}

The cable specimen was inserted into metal conduit coated with different thicknesses and was subsequently placed in the center of the furnace. The conductor-to-conductor insulation resistance and the inner temperature of the cable were monitored, and the procedure and fire scenario were the same as those stated previously. The thickness of the metal structure fire-retardant coating applied on the conduit surface ranged from $0 \mathrm{~mm}$ to $3.0 \mathrm{~mm}$; eight coating thicknesses were tested, and each was tested at least twice. The average value of the repeated tests was presented as the final result. Fig. 6a-h shows the resistance logarithm and temperature of the cable specimen versus time.

According to the curves in Fig. 6, the related cable failure parameters and protection effect of specimens with different dry coating thicknesses are presented in Table 2.

As shown in Tables 1 and 2, compared with the method of applying the fire-retardant cable coating on the cable surface directly, inserting the cable into a fire-retardant coated conduit was more effective in protecting the cable, and the resulting 


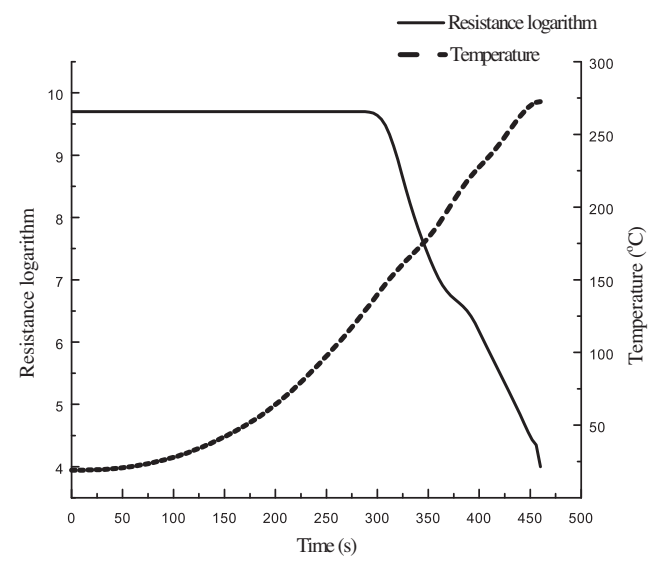

(a) Without fire retardant coating

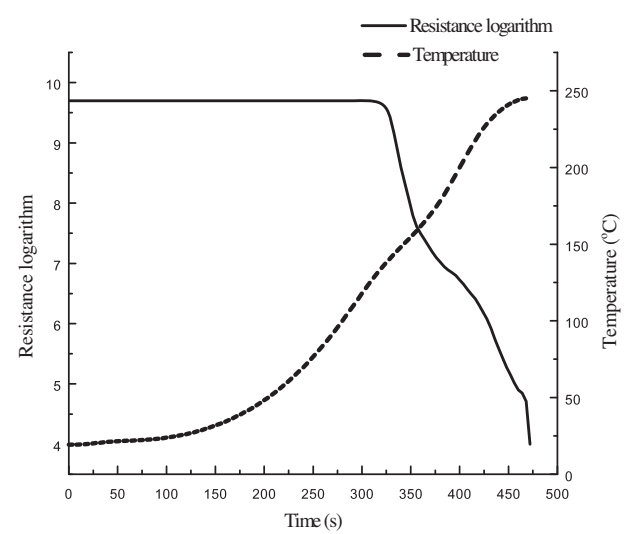

(c) Dry coating thickness of $0.57 \mathrm{~mm}$

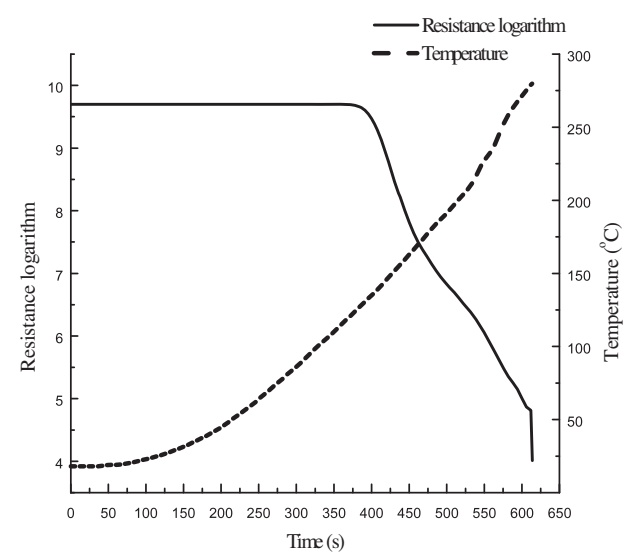

(e) Dry coating thickness of $1.47 \mathrm{~mm}$

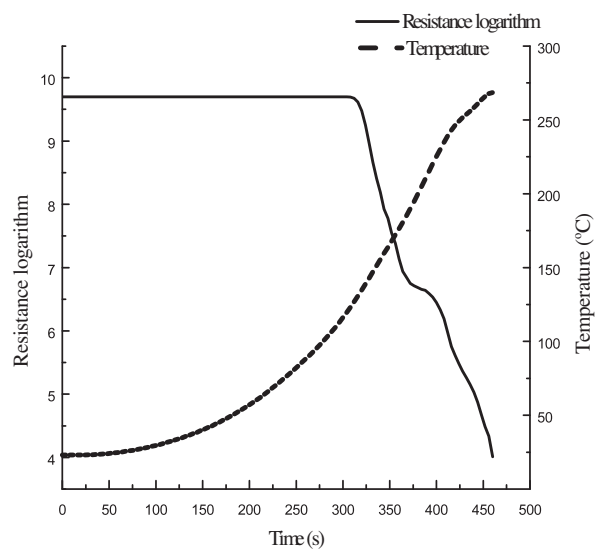

(b) Dry coating thickness of $0.23 \mathrm{~mm}$

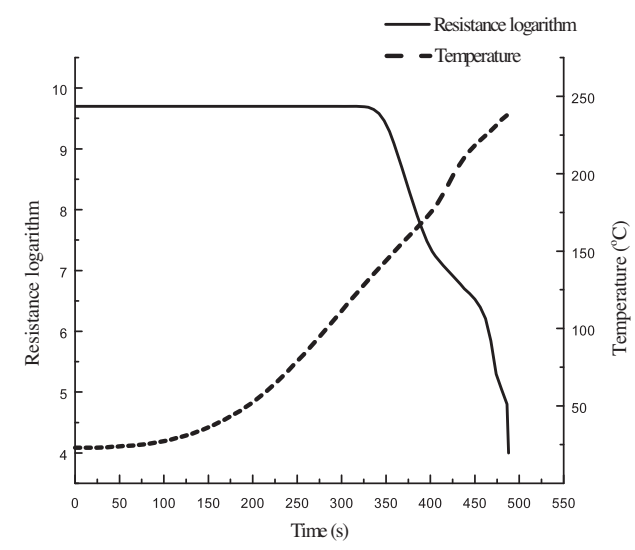

(d) Dry coating thickness of $1.01 \mathrm{~mm}$

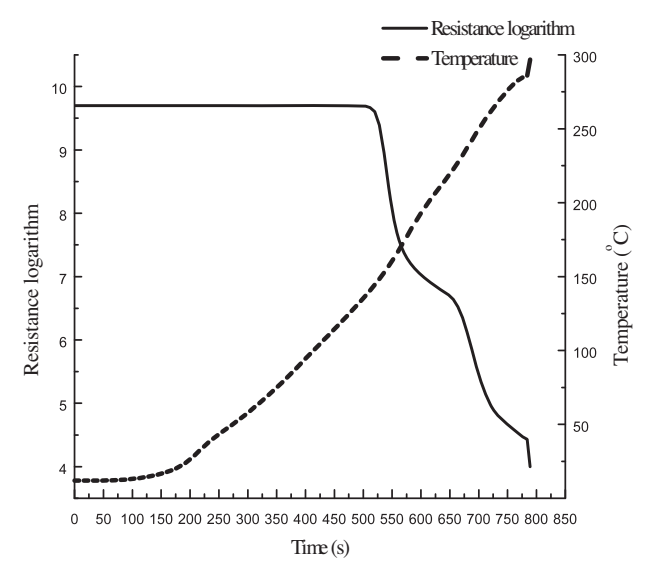

(f) Dry coating thickness of $2.05 \mathrm{~mm}$

Fig. 6. Logarithms of resistance and temperature versus time of PVC cables inserted in conduit with different coating thicknesses.

time-to-failure was much longer. Therefore, the protection method can be suitably chosen according to the retardation time required for the actual cable project.

It should be noted that the effect of the conduit itself cannot be ignored because the prolongation rate of the cable failure time reached $192.48 \%$. The conduit without a coating can also protect the cable to a certain degree. 


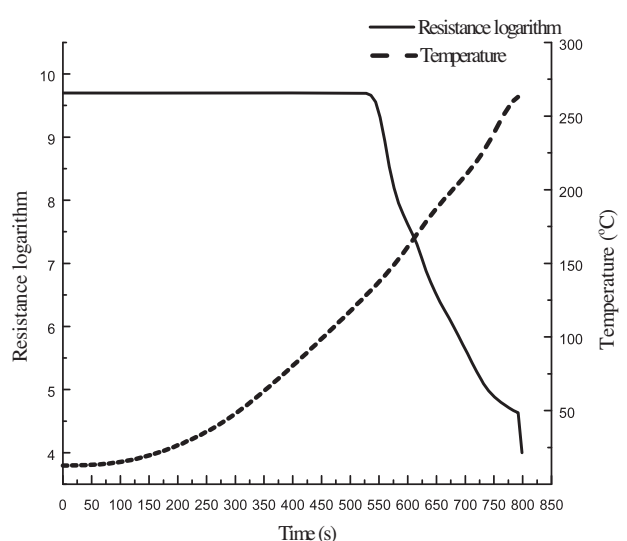

(g) Dry coating thickness of $2.46 \mathrm{~mm}$

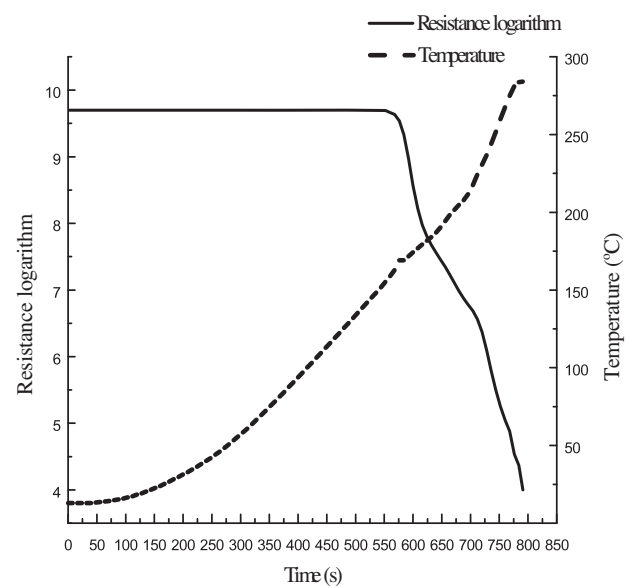

(h) Dry coating thickness of $2.96 \mathrm{~mm}$

Table 2

Protection effect of conduits with different coating thicknesses for insulation failure of PVC cables.

\begin{tabular}{lllllll}
\hline $\begin{array}{l}\text { Dry coating } \\
\text { thickness } \\
(\mathrm{mm})\end{array}$ & $\begin{array}{l}\text { Failure } \\
\text { time } \\
(\mathrm{s})\end{array}$ & $\begin{array}{l}\text { Failure } \\
\text { temperature } \\
\left({ }^{\circ} \mathrm{C}\right)\end{array}$ & $\begin{array}{l}\text { Temperature } \\
\text { inner furnace } \\
\left({ }^{\circ} \mathrm{C}\right)\end{array}$ & $\begin{array}{l}\text { Coating thickness } \\
\text { after expansion } \\
(\mathrm{mm})\end{array}$ & $\begin{array}{l}\text { Average } \\
\text { expanding } \\
\text { multiple of } \\
\text { coating }\end{array}$ & $\begin{array}{l}\text { Prolonging rate of } \\
\text { cable failure time } \\
(\%)\end{array}$ \\
\hline 0 & 310 & 147 & 572 & - & - & 5.7 \\
0.23 & 318 & 132 & 575 & 1.3 & 10.7 & 200.0 \\
0.57 & 326 & 140 & 579 & 6.1 & 10.5 & 207.5 \\
1.01 & 348 & 143 & 588 & 10.6 & 12.0 & 228.3 \\
1.47 & 400 & 135 & 608 & 17.6 & 14.1 & 277.4 \\
2.05 & 525 & 146 & 648 & 28.9 & 13.3 & 395.3 \\
2.46 & 547 & 136 & 654 & 32.7 & 9.3 & 416.0 \\
2.96 & 578 & 168 & 662 & 27.5 & 452.3 \\
\hline
\end{tabular}

With respect to the cable failure time, if the dry coating thickness is less than $1 \mathrm{~mm}$, the protection efficiency is not evident due to the thin coating layer and low expanding multiple. For example, in the tests of a coating thickness of $0.23 \mathrm{~mm}$ or $0.57 \mathrm{~mm}$, the failure time was only $8 \mathrm{~s}$ or $16 \mathrm{~s}$ longer, respectively, than that in the absence of the coating conduit. If the coating thickness was approximately $2 \mathrm{~mm}$, the failure time was prolonged significantly and the prolongation rate was also increased significantly. However, the effect was weakened when the thickness reached $3 \mathrm{~mm}$ due to the low expanding multiple and the thin expanded coating layer. Given the above analysis, the suitable range of the coating thickness is from $1 \mathrm{~mm}$ to $2.5 \mathrm{~mm}$, and the specific thickness should depend on the fire retardation time required in the corresponding cable project.

The equation for the failure time $\left(\tau_{f}\right)$ and dry coating thickness $\left(d_{c}\right)$ can be fitted as:

$$
\tau_{\mathrm{f}}=296.3+6.0+10^{5} \times d_{c}^{13}(R 2=0.97)
$$

where the units of $\tau_{f}$ and $d_{c}$ are seconds and meters, respectively.

Although the method of inserting the cable into a fire-retardant coated steel conduit is much more effective in improving the resistance to fire than the use of a fire-retardant coating alone, it should be emphasized that when compared with the resistance to fire for cables that provide electrical continuity for (15), 30, 60, 90 or even 120 min, a duration of less than $10 \mathrm{~min}$ is quite small.

\section{Conclusion}

Both of the tested fire protection methods, the application of a fire-retardant coating directly on the cable surface or inserting the cable into a fire-retardant coated steel conduit, are able to delay the failure time of polyvinylchloride (PVC)insulated power cables. The failure time is increased with the thickness of the coating.

If the fire-retardant coating is applied directly to the cable surface, the fire-retardant coating thickness should be limited to approximately $1 \mathrm{~mm}$. If the cable is inserted into a conduit with a fire-retardant coating, the appropriate range of the coating layer thickness is $1-2.5 \mathrm{~mm}$. Compared with the method of applying the fire-retardant coating on the cable surface 
directly, inserting the cable into a fire-retardant coated conduit is more effective in protecting the cable, and the failure time is much longer.

However, neither of these two methods is appropriate for protecting electrical cables that must supply power (or transmit a signal) to equipment that is required to operate for relatively long durations in the case of fire. Therefore, the usual cables, even if protected with fire-retardant coating, are unsuitable for providing power to safety installations that must continue to operate under fire conditions. The proper method for achieving acceptable resistance to fire properties is to use either cables or systems specifically designed for resistance to fire.

\section{Acknowledgement}

The authors thank engineer Ke-jian Zhang for his ideas in designing and constructing the experimental equipment.

\section{References}

[1] Pan M. Fire duration is a key factor in cable type selection. Build Elect 2006;4:48-53.

[2] James LM. Fire protection of critical circuits-a life and property preserver. IEEE Trans Ind Appl 1998;34(4):689-96.

[3] Edward DW. Fire-protective and flame-retardant coatings - A state-of-the-art review. J Fire Sci 2011;29(3):259-96.

[4] IEC Standard 332-3. Tests on electric cables under fire conditions. Part 3: Tests on bunched wires or cables, 1987.

[5] Ministry of Public Security Standard of CN GA 181-1998. General technical specifications for fire resistive coating of cable, 1998.

[6] PrEN 1366-11. Fire resistance tests for service installations - Part 11: Fire protective system for cable systems and associated components; 2010.

[7] DIN 4102 Teil 12. Fire behaviour of building materials and building components - Part 12: Circuit integrity maintenance of electric cable systems. Requirements and Testing; 1998.

[8] NBN 713-020 add. 3. Fire fighting - Fire performance of building materials and products - Fire resistance of building materials. Add. 3: Electric cables; 1994.

[9] EN 50200. Method of test for resistance to fire of unprotected small cables for use in emergency circuits; 2006.

[10] EN 50362. Method of test for resistance to fire of lager unprotected power and control cables for use in emergency circuits; 2003.

[11] Murphy JE. Determination of failure criteria for electric cables exposed to fire for use in a nuclear power plant risk analysis, a thesis submitted to the faculty of the Worcester Polytechnic Institute; January 2004.

[12] Shu ZhJ, Sun QH, Chen N, et al. Effect of protecting with conduits on insulation failure of ZR-VV cable. Fire Sci Technol 2010;29(6):473-7.

[13] Saxena NK, Suvir S, Sharma TP. Fire retardant coatings for electric cables. Paintindia 1999;2:35-7.

[14] Sharma Sunil K, Saxena NK. Surface coating and metal-based organic additives-approaches for FRSS PVC cables. J Fire Sci 2007;25(5):447-66. 